\title{
The investigation of relationship between adrenomedullin vascular growth endothelial factor in obese and calorie restricted rats
}

\author{
Muhittin Yurekli $^{1 *}$, Ayse Asiye Culum ${ }^{2}$
}

\begin{abstract}
Objective: Obesity and overweight are the most frequent chronic medical problems, and the increasing prevalence of obesity is a worldwide phenomenon. According to the data of World Health Organization (WHO) obesity affects over 300 million people. This study reports the effects of adrenomedullin (AdM) in obesity, due to its functions as arranging vascular endothelial function, and adjusting adipogenesis.

Material and Methods: Rats were separated into five groups randomly. Tissues were collected when the rats of obesity groups were gained $20 \%$ of their weights, and when the rats of calorie restricted groups were lost $20 \%$ of their weights. Then, AdM and vascular endothelial growth factor (VEGF) levels were measured.

Results: We showed that AdM application increased VEGF in all tissues of calorie restriction+AdM group, and the most spectacular effect of AdM injection was the quite elevated VEGF level of white adipose tissue (WAT) in calorie restriction+AdM group, because these individuals need passive fat depots (WAT) more than biologically active fat tissue (brown adipose tissue: BAT). Other remarkable level was in obese+AdM; AdM application lowered VEGF level by diminishing WAT depots. Contrary to this, AdM application increased VEGF levels of BAT in obese+AdM group.

Conclusion: There is a synergy between AdM and VEGF. AdM regulates the vascularization of tissues (WAT or BAT) according to the individual's requirement. Consequently, AdM may have a protective effect towards obesity, and according to metabolic situation of individual's adipose tissue, AdM application may provide consumption of energy by increasing vasculature of BAT in obese individuals.
\end{abstract}

Key words: Adrenomedullin, obesity, WAT, BAT, angiogenesis

\section{Introduction}

WHO defines obesity as an abnormal or excessive fat accumulation that disrupts health (1). Obesity is a complex, chronicle, multifactorial disease related to the interaction of genetic and environmental factors, and appears to be an important global health problem (2). Overweight represents the person weights over from standards according to height and age; obesity represents the excessive body fat. WHO developed an international classification for obesity. Body mass index (BMI) between 25-29,9 $\mathrm{kg} / \mathrm{m} 2$ reflects overweight; $30-39,9 \mathrm{~kg} / \mathrm{m} 2$ reflects obese; $40 \mathrm{~kg} / \mathrm{m} 2$ and upper reflects morbid obesity. The risk of complications caused by obesity is increased with BMI over $25 \mathrm{~kg} / \mathrm{m} 2$ (3). Obesity is in collaboration with a number of diseases including hypertension, dyslipidemia, type II diabetes mellitus, coronary artery disease, stroke, gallbladder diseases, sleep apnea, respiratory problems, breast cancer, prostate cancer, and colon cancer. There is also an increased relationship between elevated weight and mortality related to all reasons $(4,5)$. AdM is a vasodilatator peptide consisting of 52 amino acids which was firstly discovered in the tissue isolated from pheochromocytoma in 1993 (6). AdM is mainly synthesized in medulla, and also synthesized in many tissues such as myocardium, lungs, central nervous system, endothelium, vascular smooth muscle cells, and adipose tissue (7). AdM is a biologically active peptide that has various effects including vasodilatation, the regulation of vascular endothelial function, inhibition of cardiovascular alteration, adjusting adipogenesis, and decreasing insulin resistance (8). There is also AdM in circulation; the levels of plasma AdM are found increased in hypertension, obesity, heart failure, acute myocardial infarct, and atherosclerotic vascular disease $(9,10)$. Because of its biological functions, it is assumed that AdM takes part in the mechanisms act against development or progress of metabolic or cardiovascular diseases (11-13). 
Angiogenesis, or the formation of new vessels from existing vessels, plays the essential role in during and after development, adult life, several physiological (i.e. formation of corpus luteum), and pathologic conditions such as malignancy and inflammation. This event is rather important in physiological conditions $(14,15)$. Angiogenesis takes place in wound healing, development of placenta after fertilization, regeneration of inner stratum of uterus after menstruation (16). Angiogenic stage is a complex multistep process including the sequential decomposition of basic membrane, migration and proliferation of endothelial cells, and the selforganization of endothelium cells for forming capillary lumen followed by inhibition of endothelial proliferation, the new formation of basic membrane, and the accumulation of periendothelial cells $(17,18)$. Hence they are genetically stable and easily accessible via circulatory system, endothelial cells are accepted recently as the most attractive targets for treatments that aim to increase and inhibit angiogenesis $(19,20)$. Angiogenesis is very important for growing, development, and repairing of all tissues (16). Adipose tissue, particularly BAT, due to each adipocyte is surrounded by capillaries, probably is the most vascularized tissue in the body. It is actually demonstrated that angiogenesis has a considerable role in regulation of adipogenesis and obesity. Obesity related disorders such as obesity and diabetic complications, cardiovascular disorders and malignancies accompany pathological angiogenesis (21). Although inhibiting angiogenesis of adipose tissue was suggested as the first treatment approach of obesity, this concept now contradicts with the paradox that energy expenditure also may require angiogenesis $(21,22)$. Development of BAT for prevention of obesity is particularly correct. Therefore, of which negative or positive angiogenesis regulators can be used for obesity treatment is ambiguous. This situation should be related to the metabolic state of adipose tissue of angiogenesis regulator treated to individual. If the angiogenic vessels of metabolically active adipose tissue (BAT) are increased, further energy will be expended. But on the contrary, in obese individuals who have massive metabolically inactive WAT, the inhibition of angiogenesis may be more advantageous (23). Also in this study, by setting forth the thought that angiogenesis may take part in increasing the function of BAT, whether additional AdM treatment to the organism have or not any effect has been investigated

\section{Material and Methods}

A total of 60 female 12 months old Wistar rats weighting 185-255 $\mathrm{g}$ were used in the study. The rats were purchased from Inonu University Laboratory Animal Reproduction and Research Center (Malatya, Turkey) and were housed in cages in a special room at the temperature of $22 \pm 2^{\circ} \mathrm{C}$, humidity of $55 \% \pm 5 \%$, and a 12/12-hour light/dark cycle. The experiment was conducted under the protocol approved by the Inonu University. All procedures involving rats were conducted in strict compliance with relevant laws, the Animal Welfare Act, Public Health Services Policy, and guidelines established by the Institutional Animal Care and Use Committee of the university. Rats except obesity groups consumed standard diet and all rats consumed tap water ad libitum. The rats were weighed every week and at the end of the study. All rats were randomly assigned to five groups $(n=12)$ : Group 1 (Control)-the control group received standard chow, Group 2 (Obese)-the obese group consumed high fat diet (HFD) consisting of $40 \%$ calorie as fat, Group 3 (Obese + AdM)-rats consumed HFD and were treated AdM, Group 4 (Calorie restriction)-rats consumed $20 \%$ less calorie from the standard died, Group 5 (Calorie restriction + AdM)-the calorie restriction group treated AdM (24-50). AdM (Phoenix Adrenomedullin) was dissolved in distillated water, and injected to the rats intraperitoneally in a dose of $2.5 \mathrm{nmol} / \mathrm{kg}$ for four days. Rats were anesthetized intramuscularly injection of $1500 \mu \mathrm{l} / \mathrm{kg}$ ketamine and $500 \mu \mathrm{l} / \mathrm{kg}$ xylazine.

\section{Collecting and homogenization of liver, lung, brown, and white adipose tissues}

After perfusion, rats are euthanasied by removing heart. First, a piece of lung, then, a piece of liver was collected. Retroperitoneal WAT was collected by removing intestine. BAT was collected by opening dorsal of rat. Tissues were rinsed with serum physiologic, and then wrapped with labeled aluminum folio, and immediately put into liquid nitrogen. At the end of the dissection, tissues were removed from liquid nitrogen, and then stored at $-40{ }^{\circ} \mathrm{C}$ until assayed. Tissues were weighed for homogenization by putting into tarred microcentrifuge tubes. $2 \mathrm{mM}$ PBS buffer ( $\mathrm{pH} 7.3$ ) up to 20 folds of tissue $(500 \mu$ PBS buffer to $\sim 0.025 \mathrm{~g}$ tissue) was added. Tissue in the microcentrifuge tube was sliced into smaller pieces with scissor. It was homogenized 20 seconds with ultrasonificator (Bandelin Sonopuls) in ice cold. Homogenized tissues were stored at $-40{ }^{\circ} \mathrm{C}$, and centrifuged for 20 minutes at $1500 \mathrm{rpm}$ before detection.

\section{Biochemical analysis}

AdM and VEGF concentrations were assayed by Enzyme-Linked Immunosorbent Assay (ELISA) method using commercial kits according to manufacturer's instructions. AdM levels were detected with Rat Adrenomedullin (ADM) ELISA Kit CKE30105 (Hangzhou Eastbiopharm Co., Ltd.), and VEGF levels were detected with VEGF ELISA Kit EK0540 (Boster Biological Technology Ltd.) at 450 $\mathrm{nm}$ via microplate reader (BioTek ${ }^{\circledR}$ Instruments, Inc., Eon) in homogenate samples of liver, lung, white, and brown adipose tissues. Standart graphics were drawn 
according to the kits' protocols, and the AdM and VEGF levels were calculated by using standard graphics. GraphPad was used to create all graphs, and for calculation.

\section{Statistics}

The results were expressed as means \pm SEM. Paired $T$ test was performed for detecting diversity between groups, and values of $\mathrm{p}<0.05$ were considered to be statistically significant. The statistical analysis was carried out using SPSS for Windows Version 15.0.

\section{Results}

AdM and VEGF levels were measured in liver, lung, white, and brown adipose tissues of all groups. AdM and VEGF levels are shown in Tables 1 and 2. AdM is mainly synthesized in medulla, and also synthesized in many tissues such as myocardium, lungs, central nervous system, endothelium, vascular smooth muscle cells, and adipose tissue (7). It is clear that the essential physiological function of AdM is vasodilatation in both systemic circulation $(6,24,25)$ and pulmonary stratum (26). In our study, there were significant differences between control group and other groups of AdM levels of liver tissues $(\mathrm{p}<0.05)$. Control group AdM levels were higher than other groups. We can say that liver AdM levels are sensitive to dietary intake, maybe because of the changes in vasodilatation. AdM can have a role as a circulating hormone, and also can involve in the regulation of cardiovascular system, renal functions, and blood pressure as an autocrine-paracrine mediator (27). $\mathrm{AdM}$ is a biologically active peptide that has various effects including vasodilatation, the regulation of vascular endothelial function, inhibition of cardiovascular alteration, adjusting adipogenesis, and decreasing insulin resistance (8). It is indicated that AdM specific binding sites are mostly found in lung tissue (28). AdM levels of lung tissues were found higher in obese+AdM group, but lower in obese group than control group $(\mathrm{p}<0.05)$, so AdM application increased AdM level in obese+AdM group. Obesity is usually in collaboration with hypertension. Because AdM also has a detractive role in pulmonary hypertension, it can cause protective effect in obese+AdM group. The levels of plasma AdM are found increased in hypertension, obesity, heart failure, acute myocardial infarct, and atherosclerotic vascular disease $(9,10)$.
After high fat diet, adipose tissue and plasma AdM concentrations increase with the rise of body weight (13). WAT AdM levels were higher in obese, calorie restriction, and calorie restriction+AdM groups than in control group $(\mathrm{p}<0.05)$, but interestingly no significant difference was found between control and obese+AdM group ( $>0.05)$. The BAT AdM level in obese and calorie restriction+AdM groups were lower than control group, but AdM application to the obese group caused elevation according to the obese group $(p<0.05)$. Because of its biological functions, it is assumed that AdM takes part in the mechanisms act against development or progress of metabolic or cardiovascular diseases (11-13). Shibasaki et al. showed that AdM mRNA levels of epicardial adipose tissue in individuals with coronary artery disease were high, and they suggested that this could have a protective effect against the disease (29). When the AdM treated obesity group is compared with obesity group; it can be seen that AdM levels of WAT, BAT and liver reach near to the control group level. We suggest that damages caused by obesity can regress by AdM treatment (Table 1).

VEGF or VEGF-A is accepted to be the main factor which takes part in regulation of angiogenesis (30). VEGF-A is the most potent proangiogenic factor defined until now (31). Measuring this parameter gives knowledge about vascularization of the tissue. In this study, VEGF levels of liver in control group were lower than in obese group, and VEGF levels of obese+AdM group were higher than calorie restriction group, but lower than calorie restriction+AdM group $(p<0.05)$. Liver VEGF levels were significantly different between all groups $(\mathrm{p}<0.05)$. The most spectacular VEGF level in WAT was in calorie restriction+AdM group; it was extremely higher than other groups $(\mathrm{p}<0.05)$, and the other remarkable level was in obese+AdM; it can be easily seen that AdM application lowers VEGF level by diminishing WAT depots $(p<0.05)$. Contrary to this, in BAT, AdM application increased VEGF levels of obese+AdM and calorie restriction $+\mathrm{AdM}$ group $(\mathrm{p}<0.05)$, and of course levels were higher in obese+AdM group than calorie restriction+AdM group. AdM activates VEGF receptors in vascular endothelial cells (32). Evans et al. have showed synergy between AdM and VEGF in women have endometrial cancer (33).

Table 1: Adrenomedullin levels (ng/l)

\begin{tabular}{lcccc}
\hline \multicolumn{1}{c}{ Groups } & Liver & Lung & WAT & BAT \\
\hline Control & $439.32 \pm 18.12$ & $350.72 \pm 11.23$ & $235.94 \pm 6.04$ & $323.53 \pm 11.86$ \\
Obese & $286.63 \pm 16.88$ & $320.96 \pm 12.60$ & $296.10 \pm 4.73$ & $228.34 \pm 19.05$ \\
Obese + AdM & $355.64 \pm 6.54$ & $439.70 \pm 11.37$ & $246.95 \pm 6.42$ & $306.44 \pm 7.88$ \\
Calorie Restriction & $309.73 \pm 11.13$ & $370.40 \pm 16.40$ & $333.2 \pm 22.09$ & $353.68 \pm 13.15$ \\
Calorie Restriction + AdM & $268.20 \pm 20.37$ & $355.52 \pm 9.22$ & $346.03 \pm 7.27$ & $285.86 \pm 3.21$ \\
\hline
\end{tabular}

Medical Science and Discovery, 2016; 3(3): 124-9

Medical Science and Discovery, 201 
Table 2: Vascular endothelial growth factor levels $(\mathrm{pg} / \mathrm{mL})$

\begin{tabular}{lcccc}
\hline \multicolumn{1}{c}{ Groups } & Liver & Lung & WAT & BAT \\
\hline Control & $11601.27 \pm 391.98$ & $7279.38 \pm 3.65$ & $852.26 \pm 90.85$ & $902.81 \pm 8.57$ \\
Obese & $12569.20 \pm 177.64$ & $2983.48 \pm 188.87$ & $471.42 \pm 7.61$ & $408.77 \pm 19.18$ \\
Obese + AdM & $11753.90 \pm 466.39$ & $2589.67 \pm 22.45$ & $160.14 \pm 17.48$ & $7222.72 \pm 139.38$ \\
Calorie Restriction & $7991.21 \pm 75.51$ & $1685.31 \pm 169.41$ & $522.74 \pm 1430$ & $529.85 \pm 11.73$ \\
Calorie Restriction + AdM & $18441.87 \pm 941.14$ & $8105.59 \pm 306.57$ & $5121.68 \pm 154.84$ & $2227.49 \pm 122.86$ \\
\hline
\end{tabular}

Actually, VEGF levels of BAT are further higher than WAT (34). Our study supports this data in all groups except obese group. BAT VEGF levels were higher in obese $+\mathrm{AdM}$ and calorie restriction $+\mathrm{AdM}$ groups, but lower in obese and calorie restriction groups than control group $(\mathrm{p}<0.05)$. We can say that AdM injection increased VEGF levels thereby the vascularization of BAT which helps the energy expenditure in obese+AdM group, so AdM can be used against obesity (Table 2).
Morphologically it can be easily seen that AdM application significantly increased WAT depots of calorie restriction+AdM group, and BAT depots of obese+AdM group (Figures 1, 2).
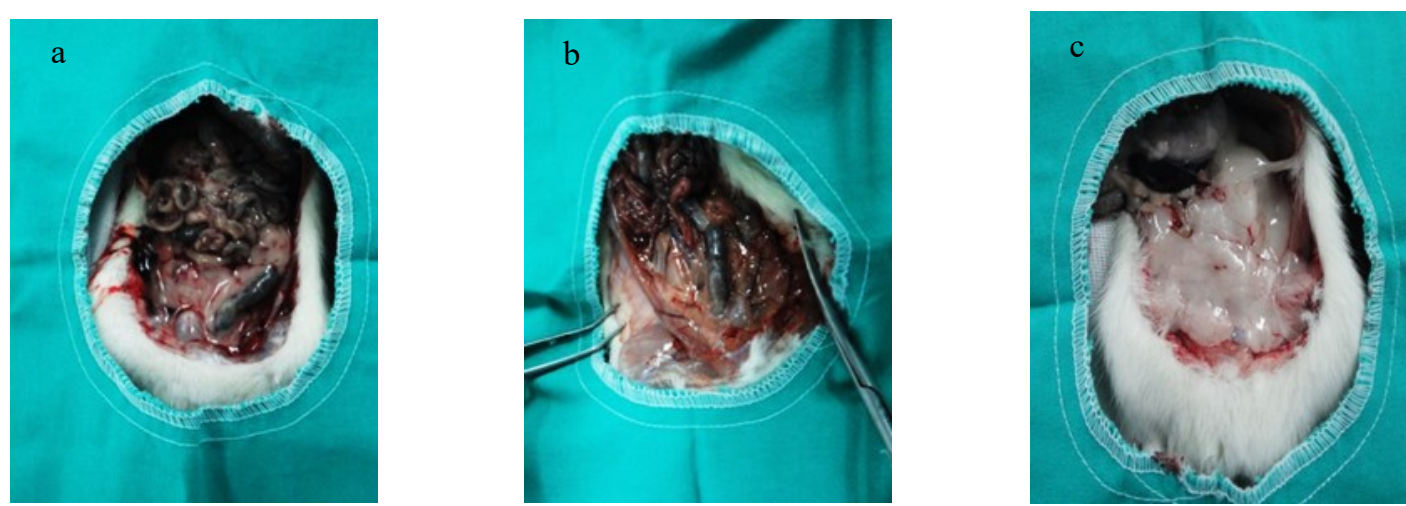

Figure 1: Abdominal white adipose tissue (a) control (b) calorie restriction, and (c) calorie restriction + AdM groups
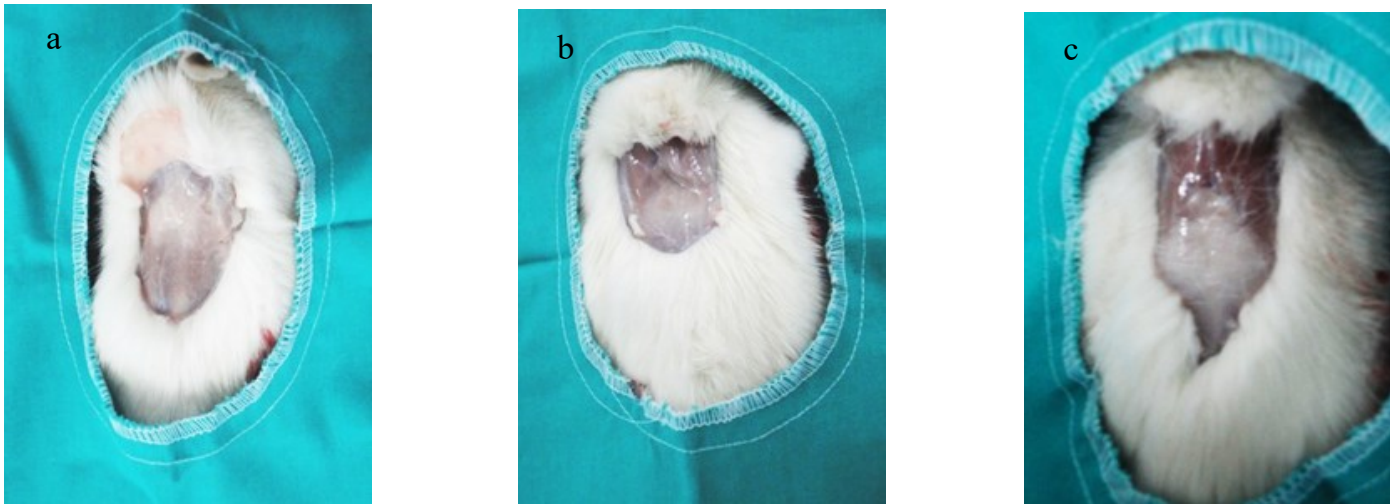

Figure 2: Interscapular brown adipose tissue (a) control, (b) calorie restriction, (c) obese + AdM groups 


\section{Discussion}

Differences are seen between angiogenic factor levels according to the dietary intake, and we also showed that there are even differences of levels between tissues in obesity and calorie restriction groups. There are many similar studies in the literature, but in our study, the effects of external applied AdM over internal angiogenic factor alterations are striking. During obesity the expanding adipose tissue becomes hypoxic, (35) and both differentiation and hypoxia induce vascular endothelial growth factor (VEGF) expression by adipocytes (36,37). AdM injection increased VEGF levels thereby the vascularization of BAT which helps the energy expenditure in obese+AdM group, and on the other hand, AdM injection also increased VEGF levels of WAT in calorie restriction+AdM group. As a result, AdM regulates the vascularization of tissues (WAT or BAT) according to the individual's requirement. AdM may have a protective effect towards obesity, and according to metabolic situation of individual's adipose tissue, AdM application may provide consumption of energy by increasing vasculature of BAT in obese individuals. The system of organism itself and conventional methods for the combat of obesity together can be regulated again by organism. AdM specific binding sites are mostly found in lung tissue. AdM has a detractive role in pulmonary hypertension, causes pulmonary vasodilatation, and inhibits bronchoconstriction created by histamine and acetylcholine. AdM application increased AdM level in obese+AdM group than obese group.

\section{Conclusion}

The increased level of AdM in lung by AdM injection also suggests that the increased vascularization of lung supplies more oxygen which is required for energy expenditure with the vasodilatation effect of AdM, so burning of fat is facilitated. We think that further investigations must be made about the effect of angiogenic factors of obese individuals' not only in adipose tissues, but also in seemingly unrelated tissues as lung.

Acknowledgements: This research was funded by Inonu University, Department of Scientific Research Projects (Project No: 2012/178).

Conflict of Interest: The authors declare no potential conflicts of interest with respect to the research, authorship, and/or publication of this article.

\section{References}

1. WHO. Obesity: Preventing and managing the global epidemic. Report of a WHO consultation on obesity Geneva June 1997. Geneva: World Health Organization, 1998. HO/NUT/NCD/98:1.

2. Comuzzie AG, Williams JT, Martin L, Blangero J. Searching for genes underlying normal variation in human adiposity. J Mol Med (Berl). 2001; 79(1):57-70.

3. Haenle MM, Brockmann SO, Kron $M$, Bertling $U$, Mason $R A$, Steinbach G, Boehm BO, Koenig W, Kern $P$, Piechotowski I, Kratzer W. Overweight, physical activity, tobacco and alcohol consumption in a cross-sectional random sample of German adults. BMC Public Health. 2006; 6:233.

4. Gregg EW, Cheng YJ, Cadwell BL, Imperatore G, Williams DE, Flegal KM, Narayan KMV, Williamson DF (2005) Secular trends in cardiovascular disease risk factors according to body mass index in US adults. JAMA. 2005; 20:1868-1874.

5. Brown CD, Higgins $M$, Donato KA, Rohde FC, Garrison R, Obarzanek E, Ernst ND, Horan M.Body mass index and the prevalence of hypertension and dyslipidemia. Obesity Research. 2000; 8(9):605-619.

6. Kitamura K, Kangawa K., Kawamoto M, Ichiki Y, Nakamura S, Matsuo H, Eto T (1993) Adrenomedullin: a novel hypotensive peptide isolated from human pheochromocytoma. Biochemical Biophysical Research Communications. 1993; 192:553-560.

7. Eto T, Kitamura K, Kato J (1999) Biological and clinical roles of adrenomedullin in circulation control and cardiovascular diseases. Clinical and Experimental Pharmacology and Physiology. 1999; 26:371-380.

8. Kato J, Tsuruda T, Kitamura K, Eto T (2003) Adrenomedullin: a possible autocrine or paracrine hormone in the cardiac ventricles. Hypertension Research. 2003; 26 (Suppl):S113-S119.

9. Kato J, Tsuruda $\mathrm{T}$, Kita $\mathrm{T}$, Kitamura $\mathrm{K}$, Eto $\mathrm{T}$. Adrenomedullin: a protective factor for blood vessels, Arteriosclerosis. Thrombosis, and Vascular Biology. 2005; 25:2480-2487.

10. Shimosawa T, Ogihara T, Matsui H, Asano T, Ando K, Fujita $\mathrm{T}$. Deficiency of adrenomedullin induces insulin resistance by increasing oxidative stress. Hypertension. 2003; 41:1080-1085.

11. Harmancey R, Sernard JM, Rouet P, Pathak A, Smih F. Adrenomedullin inhibits adipogenesis under transcriptional control of insulin. Diabetes. 2007; 56:553563.

12. lemura-Inaba C, Nishikimi T, Akimoto K, Yoshihara F, Minamino N, Matsuoka H (2008) Role of adrenomedullin system in lipid metabolism and its signaling mechanism in cultured adipocytes. Am J Physiol Regul Integr Comp Physiol 295:R1376-1384.

13. Nambu T, Arai $H$, Komatsu $Y$, Yasoda A, Moriyama K, Kanamoto N, Itoh $\mathrm{H}$, Nakao K. Expression of the adrenomedullin gene in adipose tissue. Regulatory Peptides 2005; 132:17-22. 
14. Folkman J, D'Amore PA. Blood vessel formation: what is its molecular basis? Cell 1996; 87:1153-1155.

15. Carmeliet $\mathrm{P}$, Jain RK. Angiogenesis in cancer and other diseases. Nature. 2000; 407:249-257.

16. Folkman J. Angiogenesis in cancer, vascular, rheumatoid and other disease. Nature Medicine. 1995; 1:27-37.

17. Risau W. Mechanisms of angiogenesis. Nature. 1997; 286:671-674.

18. Bohem T, Folkman J, Browder T, O'Reilly MS Antiangiogenic therapy of experimental cancer does not induce acquired drug resistance. Nature. 1997; 390:404407.

19. Bine'truy-Tournaire R, Demangel C, Malavaud B, Vassy R, Rouyre S, Kraemer M, Plouët J, Derbin C, Perret G, Mazié JC. Identification of a peptide blocking vascular endothelial growth factor (VEGF)- mediated angiogenesis. EMBO Journal. 2000; 19:1525-1533.

20. Carmeliet P. Angiogenesis in health and disease. Nature Medicine. 2003; 9:653-660.

21. Cao Y. Angiogenesis modulates adipogenesis and obesity. The Journal of Clinical Investigation. 2007; 117:23622368.

22. Xue $\mathrm{Y}$, Petrovic N, Cao R, Larsson O, Lim S, Chen S, Feldmann HM, Liang Z, Zhu Z, Nedergaard J, Cannon B, Cao Y. Hypoxia-independent angiogenesis in adipose tissues during cold acclimation. Cell Metabolism. 2009; 9:99-109.

23. Cao Y. Adipose tissue angiogenesis as a therapeutic target for obesity and metabolic diseases. Nature Reviews Drug Discovery. 2010; 9:107-115.

24. Nuki C, Kawasaki H, Kitamura K, Takenaga M, Kangawa K, Eto T, Wada A. Vasodilator effect of adrenomedullin and calcitonin gene-related peptide receptors in rat mesenteric vascular beds. Biochem Biophys Res Commun. 1993; 196:245-251.

25. Santiago JA, Garrison E, Purnell WL, Smith RE, Champion HC, Coy DH, Murphy WA, Kadowitz PJ. Comparison of responses to adrenomedullin and adrenomedullin analogs in the mesenteric vascular bed of the cat. Eur J Pharmacol. 1995; 272:115-118.

26. Nossaman BD, Feng CJ, Cheng DY, Dewitt BJ, Coy DH, Murphy WA, Kadowitz PJ. Comparative effects of adrenomedullin, an adrenomedullin analog, and CGRP in the pulmonary vascular bed of the cat and rat. Life Sci. 1995; 56:PL63-PL66.
27.

Balat A, Cekmen M, Yurekli M, Gulcan H, Kutlu O, Turkoz Y, Yologlu S. Adrenomedullin and nitrite levels in children with minimal change nephrotic syndrome. Pediat Nephr. 2000; 15:1-2:70-73.

28. Owji AA, Smith DM, Coppock HA, Morgan DG, Bhogal R, Ghatei MA, Bloom SR. An abundant and specific binding site for the novel vasodilator adrenomedullin in the rat. Endocrinol. 1995; 136:5:2127-2134.

29. Shibasaki I, Nishikimi T, Mochizuki Y, Yamada Y, Yoshitatsu M, Inoue $Y$, Kuwata T, Ogawa H, Tsuchiya G, Ishimitsu T, Fukuda H. Greater expression of inflammatory cytokines, adrenomedullin, and natriuretic peptide receptor- $\mathrm{C}$ in epicardial adipose tissue in coronary artery disease. Reg Pept. 2010; 165:210-217.

30. Ferrara N. VEGF and the quest for tumor angiogenesis factors. Nat Rev Cancer. 2002; 2:795-803.

31. Hoeben A, Landuyt B, Highley MS, Wildiers $H$, Van Oosterom AT, De Bruijin EA. Vascular Endothelial Growth Factor and Angiogenesis. Pharmacol Rev. 2004; 56:549580.

32. Guidolin D, Albertin G, Spinazzi R, Sorato E, Mascarin A, Cavallo D, Antonello M, Ribatti D. Adrenomedullin stimulates angiogenic response in cultured human vascular endothelial cells: Involvement of the vascular endothelial growth factor receptor 2. Peptides. 2008; 29:2013-2023.

33. Evans JJ, Chitcholtan K, Dann JM, Guilford P, Gavin Harris, Lewis LK, Nagase J, Welkamp AAW, Zwerus R, Sykes PH. Adrenomedullin interacts with VEGF in endometrial cancer and has varied modulation in tumours of different grades. Gyn Oncolg. 2012; 125:214-219

34. Asano A, Kimura K, Saito M. Cold-induced mRNA expression of angiogenic factors in rat brown adipose tissue. J Vet Med Sci. 1999; 61:403-409.

35. Kabon B, Nagele A, Reddy D, Eagon C, Fleshman JW, Sessler DI, Kurz A. Obesity decreases perioperative tissue oxygenation. Anesthesiology. 2004;100:274-280.

36. Claffey KP, Wilkison WO, Spiegelman BM. Vascular endothelial growth factor. Regulation by cell differentiation and activated second messenger pathways. J Biol Chem. 1992; 267:16317-16322.

37. Zhang QX, Magovern CJ, Mack CA, Budenbender KT, Ko W, Rosengart TK.Vascular endothelial growth factor is the major angiogenic factor in omentum: mechanism of the omentum-mediated angiogenesis. J Surg Res.1997;67:147-154.

Copyright (C) 2016 The Author(s); This is an open-access article distributed under the terms of the Creative Commons Attribution License (http://creativecommons.org/licenses/by/4.0), which permits unrestricted use, distribution, and reproduction in any medium, provided the original work is properly cited. All Rights reserved by international journal of Medical Science and Discovery.

Medical Science and Discovery, 2016; 3(3): 124-9 